Review Article

\title{
ChoK-ing the Pathogenic Bacteria: Potential of Human Choline Kinase Inhibitors as Antimicrobial Agents
}

\author{
Moad Khalifa, Ling Ling Few, and Wei Cun See Too \\ School of Health Sciences, Health Campus, Universiti Sains Malaysia, 16150 Kubang Kerian, Kelantan, Malaysia \\ Correspondence should be addressed to Wei Cun See Too; stweicun@usm.my
}

Received 1 April 2020; Revised 25 May 2020; Accepted 29 June 2020; Published 10 July 2020

Academic Editor: Luis Loura

Copyright ( 2020 Moad Khalifa et al. This is an open access article distributed under the Creative Commons Attribution License, which permits unrestricted use, distribution, and reproduction in any medium, provided the original work is properly cited.

\begin{abstract}
Novel antimicrobial agents are crucial to combat antibiotic resistance in pathogenic bacteria. Choline kinase (ChoK) in bacteria catalyzes the synthesis of phosphorylcholine, which is subsequently incorporated into the cell wall or outer membrane. In certain species of bacteria, phosphorylcholine is also used to synthesize membrane phosphatidylcholine. Numerous human ChoK inhibitors (ChoKIs) have been synthesized and tested for anticancer properties. Inhibition of S. pneumoniae ChoK by human ChoKIs showed a promising effect by distorting the cell wall and retarded the growth of this pathogen. Comparison of amino acid sequences at the catalytic sites of putative choline kinases from pathogenic bacteria and human enzymes revealed striking sequence conservation that supports the potential application of currently available ChoKIs for inhibiting bacterial enzymes. We also propose the combined use of ChoKIs and nanoparticles for targeted delivery to the pathogen while shielding the human host from any possible side effects of the inhibitors. More research should focus on the verification of putative bacterial ChoK activities and the characterization of ChoKIs with active enzymes. In conclusion, the presence of ChoK in a wide range of pathogenic bacteria and the distinct function of this enzyme has made it an attractive drug target. This review highlighted the possibility of "choking" bacterial ChoKs by using human ChoKIs.
\end{abstract}

\section{Introduction}

Alongside the revolutionary development of antibiotics, many bacteria adapted swiftly and developed resistance to it. Nowadays, there are no efficient ways to combat the dreadful diseases caused by these adapted bacteria. A novel solution is needed to control these diseases. More so, in this era, that is denoted by the Centres for Disease Control and Prevention (CDC) as a "post-antibiotic era" [1]. In which the development of antibiotics has been halted and the "golden era" of antibiotic development has long passed [2], particularly when resistance has developed for every antibiotic that has been introduced [3]. This predicament has emerged since researchers have not been able to keep up with the emergence of antibiotic resistance or antimicrobial resistance (AMR) [4]. This has sped up the process of AMR development, due to the continuous use of the existing antibiotics [5-7]. Therefore, AMR must be dealt with immediately.
There is no better example of bacterial resistance to antibiotics than Staphylococcus aureus (Figure 1). The eruption of the "antibiotic era" marked the AMR development of $S$. aureus towards penicillin after being developed in the 1940s [8]. This penicillin-resistant strain is known as the phagetype 80/81 strain and caused a pandemic [9]. It vaguely disappeared soon after the introduction of methicillin in 1960 [10]. Shortly after that, methicillin-resistant $S$. aureus type I (MRSA-I) has emerged and continued until the 1970s [11, 12]. Afterward, in the mid to late 1970s, MRSA-II and MRSA-III have emerged too, flagging MRSA as a pandemic, and then the 1990s marked the emergence of the smaller more mobile MRSA-IV [11].

The last line of effective treatment against MRSA is vancomycin (VAN) and daptomycin (DAP) [13]. Linezolid is still used as an alternative for vancomycin in treating MRSA [14]. Despite the discovery of those antibiotics, S. aureus has proven to be resilient. It developed AMR against vancomycin 


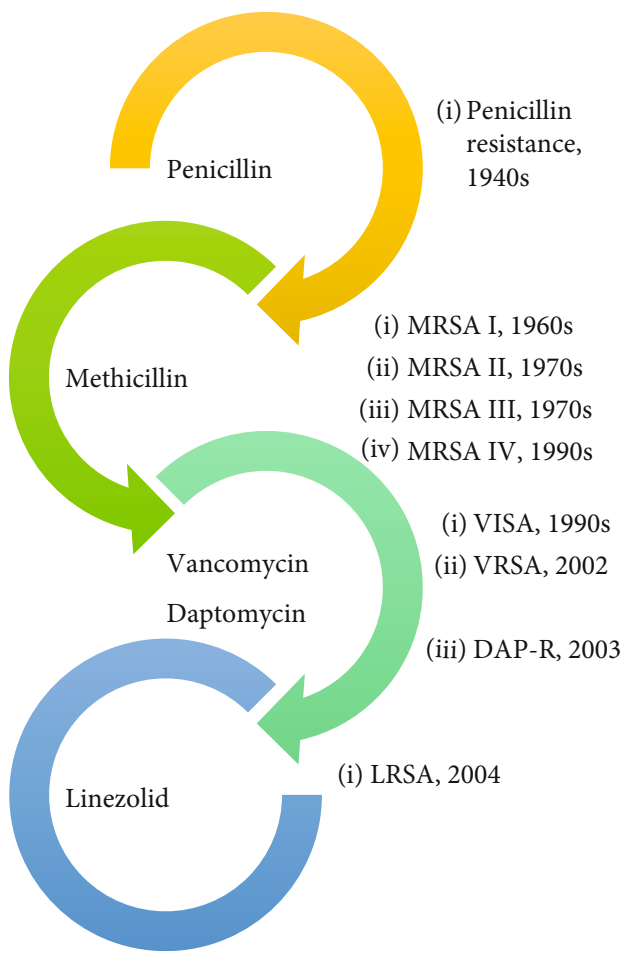

Figure 1: Trends in S. aureus treatment and resistance development.

known as vancomycin-intermediate $S$. aureus (VISA) in the 1990s, vancomycin-resistant S. aureus (VRSA) in 2002 [11], and daptomycin in 2003 (DAP-R) [15]. To combat VISA and VRSA, daptomycin [16] and linezolid [17] are used, but resistance to linezolid has also developed in 2004 alongside DAP-R [14]. The quick adaptation of $S$. aureus and many other bacteria that developed AMR needs a novel solution that puts humanity as the front runner of the race once again.

The bacteria have proven to be adept in deploying survival tactics to resist antibiotics, not just $S$. aureus but also Haemophilus influenzae [18, 19], Neisseria meningitidis [20, 21], Streptococcus pneumoniae [22-24], Streptococcus mitis and Streptococcus oralis [25-27], and many others. The strategies of AMR include (i) the alteration of the antibiotic molecule itself via destruction or inactivation, (ii) limiting the antibiotic inside the cell via reduced penetration or the expression of efflux pumps that excrete the antibiotic outside the cell, and (iii) target site alteration via a mutation in the gene, enzymatic reaction, or replacing the target site with a new site unaffected by the antibiotic [28]. Therefore, antibiotic resistance is considered a virulence factor for the bacteria as it enables a pathogen to survive not only the host defense mechanism but also drugs used to treat the infection [29].

These strategies of the microbial resistance against antibiotics are the reason behind the incredible speed of AMR development. However, other community-based reasons are behind it as well, most notably, self-medication from previously prescribed drugs [30]. The availability of antibiotics over the counter in developing countries is another major factor in AMR development [31]. These facts urge the need for increasing public awareness and developing a novel method to combat AMR. Perhaps, the key would be the usage of novel drugs designed for eukaryotic cells that have proven to be effective in prokaryotic cells, nanoparticles (NPs), that hold the potential to solve the riddle of AMR, or even a combination between those two solutions to produce a highly effective antibiotic. This might even hinder the ability of the bacteria to develop AMR against it.

One of the promising novel drugs that have the potential to be an effective antimicrobial agent is the choline kinase (ChoK) inhibitors (ChoKIs). ChoK is already an established drug target in eukaryotes [32] and this enzyme has been found to exist in most species including some prokaryotes [33]. In humans, ChoK is the first enzyme in the CDP-choline pathway for the synthesis of phosphatidylcholine (PC), the main component of the membrane lipid bilayer. PC is also synthesized by an alternative phosphatidylethanolamine-N-methyltransferase (PEMT) pathway, which occurs almost exclusively in the liver [34]. Human ChoK (hChoK) exists in alpha and beta isoforms, and the upregulation of especially hChoK alpha has been implicated in various cancers; therefore, many ChoKIs have been designed and synthesized to specifically inhibit the alpha isoform as anticancer agents [35]. The first ChoKI was a dicationic choline-mimetic hemicholinium-3 (HC-3) that was able to decrease the level of phosphorylcholine and inhibit growth factor-induced DNA synthesis in vitro [36]. However, HC-3 also produces toxic side effects by inhibiting high-affinity choline transporters and acetylcholinesterase [37]. As the potential of ChoK inhibition in the anticancer strategy became more obvious, more ChoKIs were synthesized based on HC-3 as a prototype. The firstgeneration HC-3 derivatives were bis-pyridiniums with $\mathrm{MN58b}$ as the most potent followed by second-generation bis-quinoliniums including RSM-932A or TCD-717, which showed even better antiproliferative properties and have completed phase I clinical trials $[38,39]$. Following the same pattern, more ChoKIs including EB-3D and EB-3P were synthesized for reduced toxicity and increased solubility [40]. Using in silico screening, a compound termed CK37 was found to inhibit hChoK alpha and selectively suppressed the growth of neoplastic cells [41]. The focused library screening had also identified another hChoK inhibitor, CCIC-0019 that is equipotent to MN58b and >500 times more potent than CK37 [42]. Importantly, ChoK inhibition only shows an antiproliferative effect on cancer cells but not on normal cells [39]. Besides demonstrating a promising effect on cancer $[39,43]$, ChoKIs also showed potential in targeting parasites such as P. falciparum [44-48] and Trypanosoma brucei [49] as well as modulating autoimmune diseases towards the treatment of rheumatoid arthritis [50-52]. Recently, it was suggested that ChoKIs could be useful for the treatment of acute and chronic inflammationrelated diseases as they were effective in animal models [53]. In prokaryotes, ChoK activity has been confirmed in S. pneumoniae [54] while many other bacterial pathogens possess a putative ChoK gene, such as S. aureus, Bacillus subtilis, Clostridium perfringens, and Clostridium botulinum 
[35]. This significantly indicates the possibility of using eukaryotic ChoKIs on a wide range of pathogenic bacteria especially those that have developed AMR to currently available antibiotics.

\section{Bacterial Membrane Lipids}

Lipid synthesis in bacteria is a diverse and complex process that produces many lipids that form the bacterial membranes, including phosphatidylcholine (PC), phosphatidylethanolamine (PE), phosphatidylserine (PS), phosphatidylinositol (PI), phosphatidic acid (PA), phosphatidylglycerol (PG), cardiolipin (CL), lysyl-phosphatidylglycerol (LPG), glycolipids (GLs), and diacylglycerol (DAG) [54]. Gram-positive bacteria possess a thick murein cell wall and a cytoplasmatic membrane, while Gram-negative bacteria possess outer and inner membranes, and between them exists a thin murein cell wall [55-57]. The outer membrane consists mainly of lipopolysaccharide (LPS) [58]. Lipid A, in particular, forms the outer leaflet [59] and mediates virulence [60]. Lipid A is a vital component and a drug target in Gram-negative bacteria $[61,62]$. S. pneumoniae survival and infection depend on the cell wall [63]. Choline (Cho) is essential for the cell wall [64]. Phosphorylcholine (ChoP) is synthesized from Cho by ChoK $[65,66]$. ChoP involvement in the production of teichoic acids (TA) in the form of lipoteichoic acid (LTA) attached to the membrane and cell wall teichoic acid (CTA) indicates that ChoP is also essential $[65,67,68]$. ChoP is also involved in the synthesis of type IV LTA of $S$. mitis and $S$. oralis $[69,70]$. LTA is an essential virulence factor and a potential drug target as it facilitates resistance to betalactams [71].

LPS is an important virulence factor [72], besides being an essential component. LPS can cause endotoxic shock, articulate the protective barrier of the outer membrane [55], and sensitize the host immune system [57]. It is due to the critical addition of ChoP to LPS and TA [73], even though this modification is considered rare [74]. ChoP modification aids survival of bacteria in the host $[75,76]$ and even nematodes [77], assists in recognition by host immunity [78] and adhesion facilitation [78, 79], promotes colonization [75, $76,80]$, acts as an attachment to surface protein ligands and bacteriophage anchor [81], and reduces genetic alteration and bacterial autolysis [82].

$\mathrm{PC}$ is the most abundant phospholipid in eukaryotic cells, and it is estimated to be present in $10-15 \%$ of all bacteria [ 83 , 84]. PC in bacteria acts as an intermediate for the biosynthesis of diacylglycerol-based phosphorus-free membrane lipids [84]. PC facilitates bilayer formation [83], proper membrane protein folding [85], and survival during different environmental changes [83], decreases susceptibility to antibiotics targeting bacterial membranes [75], and is critical in the microbe-host interactions [86]. Many bacteria showed diminished virulence in PC-deficient states such as Legionella sp. [87], Brucella abortus [88], and Agrobacterium tumefaciens [89]. In contrast, Pseudomonas aeruginosa showed no change in virulence in the PC-deficient state [90]. Since virulence factors should be considered in the process of selecting a novel drug target [91], ChoK would meet this criterion considering the importance of $\mathrm{ChoP}$ and $\mathrm{PC}$ in virulence.

\section{ChoK in Bacterial Lipid Biosynthetic Pathways}

As shown in Figure 2, ChoK (licA) is responsible for the phosphorylation of choline by using adenosine triphosphate (ATP) to ChoP in the cytoplasm of bacteria $[35,65,92]$. The uptake of extracellular choline is via the choline transporter $(\mathrm{licB})[67,74,93]$. Afterward, ChoP is activated into CDP-choline in the cytoplasm by phosphorylcholine cytidylyl transferase (licC) utilizing cytidine triphosphate (CTP) $[35,92]$. ChoP is then transferred from CDP-choline by phosphorylcholine transferases such as licD in Gramnegative $H$. influenzae to LPS or licD1 and licD2 in Grampositive $S$. pneumoniae to preteichoic acid for the synthesis of TA $[84,94,95]$. Lastly, TA is incorporated into the cell wall and membrane by teichoic acid flippase $(t a c F)$ [96]. In eukaryotes, the CDP-choline is used to synthesize PC by choline phosphotransferase (CPT); a similar step has recently been reported in Treponema denticola, which is catalyzed by 1,2-diacylglycerol choline phosphotransferase [97]. It is worth noting that although PC could be found in only about $15 \%$ of all bacteria [84] and ChoP produced by ChoK (licA gene product) might be rare [74], the licA gene homologs have been predicted in a number of pathogenic bacteria. Further research to confirm the activities of these putative ChoKs is required to realize the potential of using ChoKIs to fight against infections caused by more diverse species of bacteria.

Since PC synthesis by the CDP-choline pathway is unique for certain species of Treponema [97], it is important to know the other pathways for PC synthesis that have been reported in prokaryotes. There are three other pathways for PC synthesis in bacteria (Figures 3(a)-3(c)) [54, 84, 86]. The PE methylation pathway (Figure 3(a)) [54, 83], where $\mathrm{PC}$ is synthesized from PE in a sequence of three steps catalyzed by phospholipid $N$-methyltransferase (PLMT) with methyl donor $S$-adenosylmethionine (SAM) to form monomethylphosphatidylethanolamine (MMPE), dimethylphosphatidylethanolamine (DMPE), and then PC [54]. MMPE is the last product in a few bacteria such as Xanthomonas campestris [98]. PE is produced from CDP-DAG by condensing it with serine at first by phosphatidylserine synthase (PSS) to form PS, which is decarboxylated to PE by phosphatidylserine decarboxylase (PSD) [54]. CDP-DAG on the other hand is produced from PA by CDP-DAG synthase [54] Secondly, the phosphatidylcholine synthase (Pcs) pathway (Figure 3(b)) [99] is comprised of a single step of condensing CDP-DAG with Cho by the Pcs enzyme [54, 99]. Finally, the glycerophosphorylcholine (GPC) pathway (Figure 3(c)) $[54,86]$ was reported only in $X$. campestris [98], S. mitis, and S. oralis [86]. In X. campestris, extracellular GPC is transported and converted via two-step acyl-CoAdependent acylation to lysophosphatidylcholine (LPC) by unknown enzymes and then to PC by acyltransferases $X c_{-}$ 0188 and Xc_0238 [98]. Besides the abovementioned pathways, PC is also obtained via acylation of lysophospholipids 


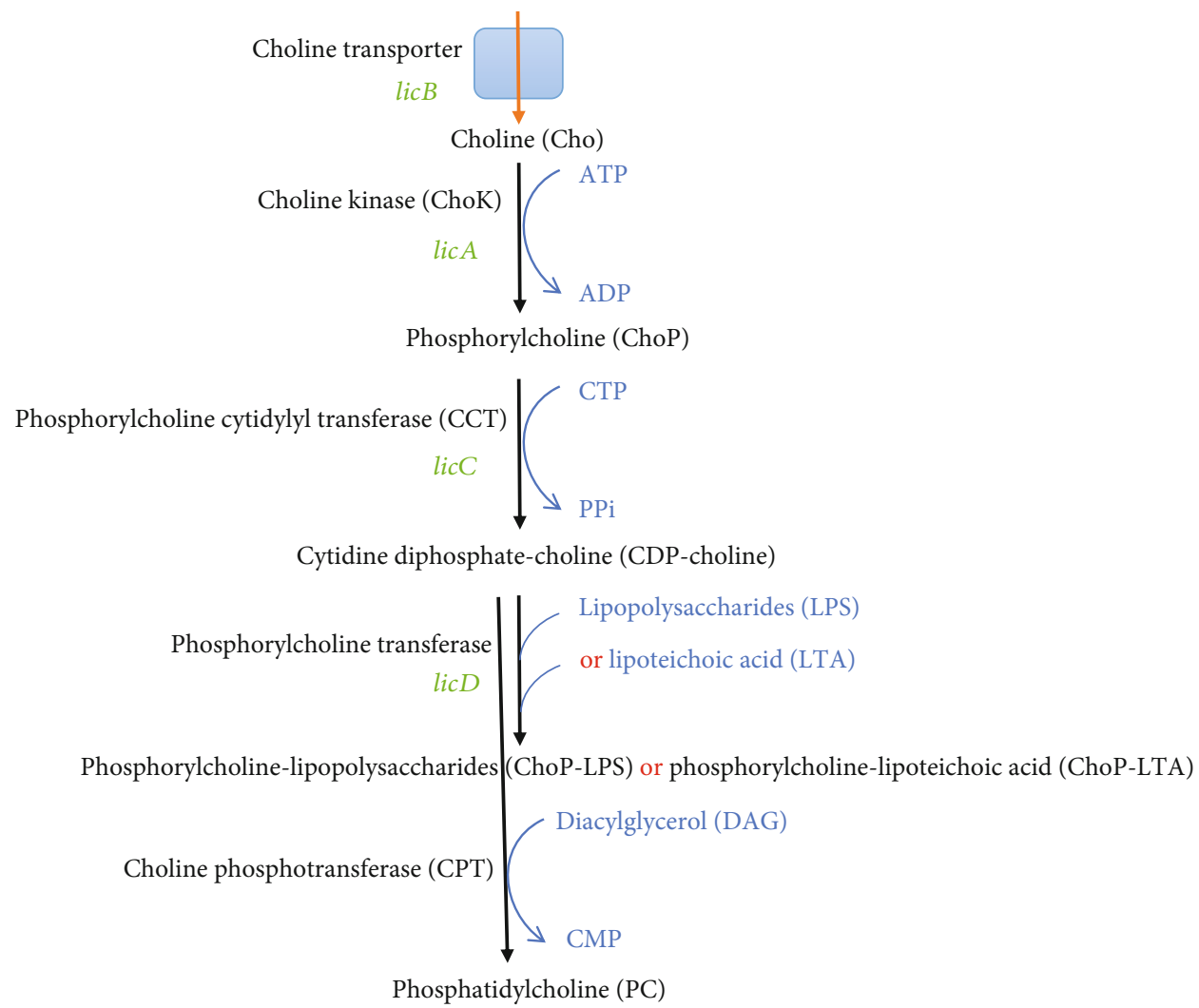

Figure 2: Pathways involving ChoK in the bacterial synthesis of ChoP-LPS, ChoP-LTA, and PC. The genes encoding for the responsible enzymes are in green and substrates are in blue.

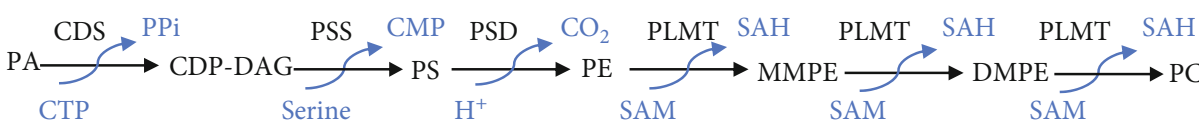

(a)

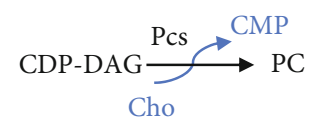

(b)

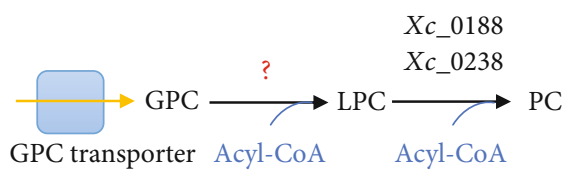

(c)

FIgure 3: Phosphatidylcholine biosynthetic pathways in bacteria other than the CDP-choline pathway: (a) PE methylation pathway; (b) Pcs pathway; (c) GPC pathway. Abbreviations not described in the text: PPi: inorganic pyrophosphate; CMP: cytidine monophosphate; SAH: Sadenosylhomocysteine.

[100]. How these alternative PC and other phospholipids biosynthetic pathways react, during inhibition of ChoK in bacteria to sustain growth requires further investigation to fully assess the potential of ChoKIs as antimicrobial agents.

\section{Eukaryotic ChoKIs on Parasites}

Unlike bacteria, the use of eukaryotic ChoKIs on parasites has gained more attention. One of the most interesting examples is the malarial parasite, P. falciparum that has developed chloroquine resistance and urgently needs novel drugs to control the disease [44]. ChoK is the first enzyme in the CDP-choline pathway for the synthesis of PC, the major
(40 to $50 \%$ of total phospholipids), and the essential phospholipid in the membrane of $P$. falciparum $[45,48]$. Inhibition of de novo PC synthesis by choline analog has been suggested as realistic malaria therapy even against pharmacoresistant strain [101]. Thus, inhibition of $P$. falciparum ChoK (PfChoK) was regarded as a potential antimalarial strategy. It was found that the primary sequence and tertiary structure of $P f C h o K$ catalytic sites are conserved compared with other ChoKs [44]. PfChoK is expressed at a higher level during growth phases of this parasite [47] and it becomes less viable after ChoK inhibition [48]. Second-generation (MN58b) and third-generation (RSM-932A) ChoKIs with minimal toxicity to humans have been shown to inhibit 
PfChoK and led to reduced parasitemia by impairing the maturation and invasion of $P$. falciparum [44]. MN-58b and RSM-932A demonstrated the potent antiplasmodial effect by inhibiting $P f C h o K$ in the low nanomolar range [44] possibly due to high sequence identity ( $69 \%$, when only conserved residues of ATP and Cho binding sites are considered) at the active sites compared to hChoK [45].

Other parasites utilizing the CDP-choline pathway for the synthesis of PC and carrying the ChoK gene are also potential targets for ChoKIs, most notably Toxoplasma gondii, which exhibits drug resistance [102], plasticity of biomass creation and gene expression [103], and nucleotide and central carbon metabolism resilience [104, 105]. Disruption of the CDP-choline pathway for PC synthesis and membrane biogenesis by pharmacological inhibition of T. gondii ChoK has been proposed as an effective way to arrest the growth of this organism [103].

Entamoeba histolytica is another deadly parasite that exhibits drug resistance with confirmed gene encoding active ChoK [106]. Therefore, EhChoK can also be tested for inhibition by ChoKIs. It must be noted that nematode parasites have also demonstrated other pathways of PC synthesis [107]. One such example is Leishmania major, in which despite having ChoK in the CDP-choline pathway for PC synthesis, this parasite has shown sustained growth in phosphorylcholine cytidylyltransferase- (CCT-) deficient state, which suggests the utilization of other alternative pathways of PC synthesis [108].

\section{Eukaryotic ChoKIs Have the Potential to Be Prokaryotic ChoKIs}

The use of eukaryotic ChoKIs for the inhibition of bacterial growth was first demonstrated by HC-3 inhibition of Gram-positive S. pneumoniae ChoK (SpChoK) [35]. Subsequently, two more eukaryotic ChoKIs, the MN-58b and RSM-932A, both are more potent inhibitors of human hChoK, were found to exhibit several orders of magnitude stronger inhibition against SpChoK than HC-3 [92]. Based on these examples, it was suggested that many drugs used to control diseases in eukaryotes have the potential to be used against the same protein targets in prokaryotic pathogens, especially whenever it meets certain criteria including conserved primary and tertiary structures [92]. SpChoK showed conservation of tertiary structure and catalytic site residues with hChoK $[63,92]$ and that could be the reason for the established eukaryotic ChoKIs (previously tested as anticancer drugs) to effectively inhibit $S p C h o K$ activity and distort the cell wall of $S$. pneumoniae [35].

The promising outcome from $S p C h o K$ inhibition highlights the potential of using existing ChoKIs for pathogenic microorganisms with ChoKs having high amino acid sequence homology with the human enzyme at the active sites. Figure 4 shows the sequence alignment of the Cterminal of hChoK and putative ChoKs from some pathogenic bacteria showing conserved amino acids at the active sites. The conserved aspartate and asparagine in the Brenner's phosphotransferase motif have been shown to interact with the phosphate group of phosphorylcholine (product) in the solved structure of human ChoK (Asp-306 and Asn311 ), and the aspartate residue is critical for catalytic activity [109]. In the ChoK motif, the conserved aspartate is important for coordinating magnesium ion for catalysis of the human enzyme (Asp-330) and mutation of this amino acid resulted in total loss activity [109]. Besides sequence conservation at the catalytic sites, conservation of amino acids previously identified to interact with ChoKI is also a crucial supporting evidence for the use of eukaryotic ChoKIs against bacteria ChoKs. Based on the crystal structure of hChoK alpha-HC-3 complex [110], several hydrophobic hChoK alpha residues interacting with HC-3 (inverted triangles in Figure 4) could also be found in bacteria ChoKs. Particularly, Trp-420, Trp-423, and Tyr-440 in hChoK alpha are also present in all the bacteria ChoKs except $V$. cholerae and $S$. aureus. Tyr-437 in hChoK was substituted with a different hydrophobic phenylalanine residue in the bacteria. Leu- 419 (blue circle in Figure 4) of hChoK alpha that is neighbouring the active site and influences the plasticity of $\mathrm{HC}-3$ binding groove was also relatively conserved (six out of twelve compared sequences) among bacterial ChoKs. Based on the sequence conservation of the active sites and some residues interacting with HC-3, most of these bacterial ChoKs, if confirmed to be active and expressed in the respective organisms, could be potential targets of human ChoKIs.

\section{Bacteria with lic Operon and ChoK Gene}

The study of the operon or the cluster of genes that usually code for proteins in the same metabolic pathway has been conducted to predict the presence of a certain pathway [84]. The lic operon responsible for the CDP-choline pathway remains studied in few bacteria only. These bacteria include S. pneumoniae, S. mitis, S. oralis, and H. influenzae.

In $S$. pneumoniae, the lic operon contains three regions [67]. lic1 encodes for Cho transporter, the ChoK, and phosphorylcholine cytidylyl transferase, which are expressed by licB, licA, and lic $C$ genes, respectively. The lic1 region also contains tarJ gene encoding NADPH-dependent alcohol dehydrogenase for ribitol-phosphate synthesis and tarI gene encoding cytidylyl transferase for cytidine-diphosphate synthesis. lic2 region contains licD1 and licD2 genes that code for phosphorylcholine transferases and the tacF gene for teichoic acid flippase. The remaining lic3 region contains the licD3, spr1221, spr1222, spr1223, and spr1224 genes [67].

S. mitis and S. oralis are closely related to $S$. pneumoniae. In $S$. oralis, licl contains $l i c B$, licA, licC, tarI, and tarJ genes, while lic4 contains licd3, licd4, tacF, aroK, aroA, pheA, and others such as sor_0763 and sor_0759; however, in S. mitis, lic1 contains licB, licA, licC, tarI, and tarJ; lic2 contains licD1, licD2, and tacF genes; and lic3 contains licD3, aroK, aroA, pheA, and others such as smi0766 and smi_0768 to smi_ 0771 [67]. In $H$. influenzae, the lic operon contains three regions: lic1 contains the licB, licA, licC, and licD genes; lic2 encodes for Gala(1-4)bGal; lic3 contains galE gene encoding for galactose epimerase [112]. Additionally, $H$. influenzae undergoes phase variation in the expression of LPS leading to a variety of oligosaccharide epitopes [113]. Interestingly, 
Human-CKalpha
K. pneumoniae
P. aeruginosa
B. cenocepacia
T. pallidum
H. influenzae
N. meningitidis
Bacillus-sp.
C. botulinum
S. pneumoniae
M. tuberculosis
V. cholerae
S. aureus

Human-CKalpha

K. pneumoniae

P. aeruginosa

B. cenocepacia

T. pallidum

$\mathrm{H}$. influenzae

N. meningitidis Bacillus-sp.

C. botulinum

S. pneumoniae

M. tuberculosis

V. cholerae

S. aureus

Human-CKalpha

K. pneumoniae

P. aeruginosa

B. cenocepacia

T. pallidum

$H$. influenzae

N. meningitidis

Bacillus-sp.

C. botulinum

S. pneumoniae

M. tuberculosis

V. cholerae

S. aureus

Brenner's motif

ChoK motif $\checkmark$

298 SPVVFCHNDCQEGNILLLEGRENSEKQKLMLIDFEYSSYNYRGFDIGNHFCEWMYDYSYE 357

185 LDLVPCMNDTLAGNFMLNER------GDIRLVDFEYASNNDRCYELALWFGEMFFTPQ-- 236

184 VDLAPCMNDTLAGNFMLNAA------AEVRLVDFEYASNNDRHYELALWFGEMFFAPD-- 235

186 VDLAPCMNDTLAGNFMLDAA------HRVMLVDFEYASNNDRYYELAMWFGEMFFDEQ-- 237

432 KPCVLTHVDLTPDNFLLCDG------S-AQLIDWEYAGMCDPLVDIAMF SLYAHFNTA-- 482

197 IILRPCHNDLVPENMLLQDD------R-LFFIDWEYSGLNDPLFDIATIIEEAHLSKE-- 247

145 LPLRPCHNDLVPENMLLQGE------G-LFFIDWEYSGMNDPLFDLAAVIEEGRMPSE-- 195

174 NSTHPCHNDTVPENFVVNDK------GEAYLIDWEYSGMNDPAWDIAAYILESKLTEE-- 255

499 RVEVPSHNDLVSENLVKDTE------GRIYLIDWEYSGINDDMWDLAALSLENNF SED-- 550

168 VDRKSCHIDLVPENFIESPQ------GRLYLIDWEYSSMNDPMWDLAALFLESEFTSQ-- 219

173 LNICPCHNDPVPENFIYNDN------G-YYLIDWEYSGMNDNIWDIAALCEESHLSDN-- 223

138 EHSCLISGDTNDGNWGIRQN------GELVLFDWERFGYGSPAIDLAPLVQGLGSMDE-- 189

151 RFFTVVHGDVNHNNWLLSDR------DELFLVDWEGAMIADPAIDIGMLLYNYVPQQQ-- 202

$$
: *^{*}: \quad::
$$

$\nabla$

358 KYPFFRANIRKYPTKKQQLHF I SSYLPAFQNDFENLSTEEKS I IKEEMLLEVNRFALASH 417

237 ---------------IEQELLEDYFGKT--------DN-------KLFARVQVHKYLAD 265

236 -------------MELALTEDYFGAV-------TP------QTLARVYVNKATAD 264

$238--------------V E L E L I E E Y F G R V--------G P-------R E I A R V Q L Y K A L A D 266$

$483---------------Q I E D L M Y R Y F Q R N--------$ PHG------EERLRVFCYIALGG 512

248 -------------AADFLLETYCNQT-------NKYHKTEFQIAHKRLKIHRFCQN 283

196 --------------AADCLLEAYFAGG-------ASD-GISARDAAARLTIHRFCQN 230

$256------------P I R D F L L D Y Y G Q W------P S A-----A E E L K I K A F M L A Q D 285$

$551--------------D T E L M F R L Y F N G E-------A D-----D$ DNSRKRLLIHQISQD 580

$220-------------$ EEETELSHYESDQ-------T------PVSHEKIAIYKILQD 248

$224-------------D E N I F L N H Y L N E Y-------S S E----S E A I K E K I L I Y K A C Q N 255$

190 --------------YASIIERYTQHN-------SS---FAADE--------LTKH 212

$203----------------W S E W L E T Y G V Q E--------S L---N L N K R---------M---222$

\section{○ 7 V}

418 FLWGLWSIVQAKISSIEFGYMDYAQAREDAYFHQKRKLGV---------------- 457

266 MKWSTWAIIQHHVADIDFDFSKYGAWKNLRARSVLNHPDWENWLRA----------- 311

265 LKWSTWAMVQHAVSQIDFDFYKYGALKHSRARSVIHDSRWETWLRQV--------- 311

267 LKWSAWAMVQRSVSRIDFDFYKYGIWKYMRARTVMQDIRWESWLRQV--------- 313

513 FLWSLWTSYKQALG---ISFGDYGLKMYRYAKEYYEAVQTLLKTHRADHAERKM--- 563

284 VLWELWTKVKEEHG---ENEGDYALKRLDAAFKLLEELP----------------- 319

231 VLWFLWTKVKEEQG---EDFGGYAARRLAAAFELSAVLP----------------- 266

286 LLWTVWALVRHYHG---DDFLDYCYFRYERFRKNIKQLNHVSEYTISGIVKN----- 334

581 LLWAVWTLIKENEG---DDFGTYGIDRYNRGKENLNKLEAEF-------------- 619

249 TIWSLWTVYKEEQG---ADFGYYGVNRYQRAVKGLASYGGTDEK------------- 289

256 FLWSIWTLIKEKNE---NLFGTYGIDRYKKCQKQMNLHRKKYATTE----------- 298

213 LVIAKCWIVIEVINILISRNKPEAAIYIDWYK-----KNLPAWLGAVENAL------ 258

$212----K W Y T V I Q S I G----------L V Q W Y E E Q K R Y K D M N T W L K F L N E V M N S N M F I ~ 263$

FIgURE 4: Amino acid sequence alignment of ChoK C-terminal from human and selected pathogenic bacteria. Sequence alignment was made by Clustal Omega available at https://www.ebi.ac.uk/Tools/msa/clustalo/ [111]. Asterisk, colon, and period indicate single fully conserved residue, conservation between groups of strongly similar properties, and conservation between groups of weakly similar properties, respectively. Inverted blue triangles indicate the hydrophobic residues forming interactions with HC-3 in hChoK alpha [110]. The blue circle indicates the hydrophobic residue that influences the plasticity of HC-3 binding groove. GenBank accession numbers for HumanCKalpha (NP001268.2), K. pneumoniae (PUG97579.1), P. aeruginosa (PTZ28970.1), B. cenocepacia (ODN63053.1), T. pallidum (APT97059.1), H. influenzae (AIB45944.1), N. meningitidis (SPY01484.1), C. botulinum (KON14313.1), S. pneumoniae (VTW72173.1), Bacillus sp. (AFS006103), M. tuberculosis (SGD50227.1), V. cholerae (QEO43700.1), and S. aureus (AXU08810.1) are shown.

thousands of bacterial species have demonstrated to possess a putative ChoK gene [92]; confirmed ChoK activity has also been reported for Gram-negative $H$. influenzae and the Gram-positive S. pneumoniae [63]. These data indicate the potential existence of the ChoK gene, and that however different the organization of the lic operon is, it still encodes for the enzymes necessary for the CDP-choline pathway in different bacterial species. This demonstrates the need for more research in the confirmation of ChoK gene function and lic operon to combat pathogenic microbes by inhibiting ChoK activity.

It is interesting to note that the choline transporter (licB gene product) could also be a potential target for human ChoKIs like HC-3 and some of its derivatives that showed the undesired neuronal toxicity due to perturbation of choline transport into the cells. These inhibitors could be repurposed for choline uptake inhibition in pathogenic bacteria to achieve the same effect as inhibiting ChoK. Since there is no 
evidence for de novo synthesis of choline in prokaryotes and because choline uptake from exogenous sources is energetically more favorable than de novo synthesis, different uptake mechanisms for choline transport across the membrane have evolved in bacteria [114]. Inhibition of choline transporters can be expected to produce a detrimental effect on bacterial growth by blocking the supply of choline for the synthesis of cell wall and LPS components (as described above), glycine betaine (an important osmoprotectant) [115] or trimethylamine (produced by anaerobic degradation of choline and used as a carbon source or precursor to marine osmolyte or greenhouse gas, methane) [116]. Table 1 shows a list of pathogenic bacteria containing ChoKs and choline transporters. Based on this idea, choline uptake inhibitors developed for human neurons such as ML352 [117] could also be tested for blocking bacterial choline uptake system. More inhibitor candidates would certainly improve the outcome as bacteria, including $H$. influenzae might have multiple mechanisms for choline uptake other than licB transporter [93]. Besides choline transporters, another likely target of ChoKIs is the choline-binding proteins (CBPs) that play important roles in the viability and virulence of pneumococcus and related species. The CBPs have been proposed as targets for the design of new antimicrobials [91].

\section{Nanoparticles as a Delivery Vehicle for ChoKIs}

Nanoparticles (NPs) ranging from inorganic nanomachines to organic molecules like proteins, delivered as nanocapsules or nanospheres, are nanomedicines (as referred to by the National Institutes of Health) that are ushering a new era in disease diagnosis, treatment, and prevention [136]. NPs have a huge impact on the diagnosis of pathogens. In fact, if combined with theranostics, they would allow the combination of diagnosis, therapy, and monitoring in one platform [137]. According to Bobo et al. in the year 2016 [138], there were 51 nanomedicines approved by the USFDA, including the nanoformulations for antibacterial purposes. Various types of NPs used in the treatment of microbial infections have been discussed in a recent review by Lee et al. [139] and Yeh et al. [140]. NPs can be designed to carry antibiotics specifically to the pathogen at the site of infection. For example, to enhance antibiotic delivery to lung infection, NPs are incorporated into swellable microparticles for better deposition to deep lung [141]. At the site of infection, chargebased localization of NPs to the bacterial cell wall by using cationic peptide can be employed. More specific localization of NPs to the pathogen can be achieved by conjugating bacterium-specific ligand (small molecules, proteins, antibodies, or aptamers) to the NPs. Similarly, pathogens that invade and survive inside host cells can be specifically targeted by designing NPs that trigger uptake by the host cells [141]. In addition, surface charge-switching PLGA-PLHPEG NPs were used to shield nontarget interaction at $\mathrm{pH}$ 7.4 and releasing the transported drug only in low $\mathrm{pH}$ caused by bacterial metabolism or host immune response, thus increasing the efficacy of antimicrobics [142]. The use of sil-
TABLE 1: List of pathogenic bacteria containing ChoK and choline transporter. The presence of these proteins in the bacteria was supported by related literature or representative GenBank accession numbers to the putative ChoKs.

\begin{tabular}{|c|c|c|}
\hline \multirow[t]{2}{*}{ Bacterium } & \multicolumn{2}{|c|}{$\begin{array}{l}\text { Supporting literature or GenBank } \\
\text { accession numbers }\end{array}$} \\
\hline & ChoK & Choline transporter \\
\hline Bacillus subtilis & AFS006103 & {$[118,119]$} \\
\hline Burkholderia cenocepacia & ODN63053.1 & {$[120,121]$} \\
\hline Clostridium botulinum & KON14313.1 & {$[122,123]$} \\
\hline Haemophilus influenzae & AIB45944.1 & [93] \\
\hline Klebsiella pneumoniae & PUG97579.1 & {$[124,125]$} \\
\hline Mycobacterium tuberculosis & SGD50227.1 & {$[126,127]$} \\
\hline Neisseria gonorrhoeae & {$[128,129]$} & {$[128,130]$} \\
\hline Neisseria meningitidis & {$[128,129]$} & {$[128,130]$} \\
\hline Pseudomonas aeruginosa & {$[128,129]$} & {$[131]$} \\
\hline Staphylococcus aureus & AXU08810.1 & {$[132]$} \\
\hline Streptococcus mitis & OOS15958.1 & {$[67]$} \\
\hline Streptococcus pneumoniae & {$[63]$} & {$[67,74,86]$} \\
\hline Treponema denticola & {$[97,133]$} & {$[97]$} \\
\hline Treponema pallidum & [133] & {$[97]$} \\
\hline Vibrio cholerae & QEO43700.1 & {$[134,135]$} \\
\hline
\end{tabular}

ver NPs could also enhance antibiotic activity against bacteria [143].

NPs attack bacteria via multiple mechanisms, mainly through oxidative stress [144], prevention of biofilm formation [145], and direct action on the cell wall [146]. However, when combined with an antibiotic, it will help restore the antimicrobial efficacy [147]. NPs can act solely and combat bacteria alone or act as a vehicle or delivery system for antibiotics [1,148]. More importantly, NPs can deliver drugs to the site of action [136] with minimal side effects [148], have the localization of an ample amount of the drug to overcome drug resistance [149], and even have the potential to prevent AMR from occurring [150].

Using an efficient targeted system, CARG-conjugated vancomycin-loaded nanoparticles that specifically target $S$. aureus have managed to subdue infection with lower systemic dose to minimize any potential side effect [151]. Other examples of antibiotics delivery by NPs include nanoparticles chelated with amoxicillin or ampicillin against resistant strains of E. coli, $\mathrm{ZnO}$ nanoparticles complexed with ciprofloxacin against $S$. aureus and E. coli, rifampicin and thymopentin inside micro-nanoparticle hybrid to treat deep lung infections, and ciprofloxacin in nanoparticle-hydrogel hybrid material (NP-gel) to inhibit E. coli forming biofilm [141]. Formation of biofilms by pathogenic microorganisms has been directly linked to chronic infections with increased disease severity, and NPs have provided the perfect platform to combat bacteria in biofilms through direct interaction with the extracellular polymeric substances (EPS) [152, 153]. Despite the much lower toxicity of the later generations of ChoKIs [40] compared to HC-3, packaging and delivery of ChoKIs to the site of action or infectious agents would allow high local concentrations while minimizing systemic side 
effects to the human host. The high local concentration of antibiotic is important because less than minimum inhibitory concentration (MIC), especially in the intracellular compartment of infected host cells, could result in the development of drug resistance [154]. Based on the advantages and versatility of NPs, we hypothesize that NP delivery of ChoKIs to the site of infections could increase its efficacy and specificity while reducing potential side effects. Depending on the types of infections, NPs with bacterium-specific ligands, antibiofilm properties, or features for internalization into host cells for intracellular infections could be selected as vehicles for ChoKIs while shielding the effect of the inhibitors from any human ChoKs or other unspecific targets.

\section{What the Future Holds (Research Perspectives)}

Despite the progress made in understanding the biochemical pathways for the synthesis of bacterial phospholipids and the confirmation of ChoK activities in prokaryotes, many questions still need to be answered to fully adopt ChoKIs for antibacterial in solving the AMR problem. Is there an alternative or compensatory pathway alongside the CDP-choline pathway involving ChoK for the synthesis of PC in the target pathogenic bacteria? How potent are ChoKIs developed as anticancer agents when used on bacterial ChoKs? Will there be any side effects on the host? Yet, considering the widespread AMR in so many human pathogens, the desperate search for new antimicrobial agents including ChoKIs warrants more efforts to address the above questions. Some of the possible answers or solutions have been discussed in this review, and the efficacy of ChoKIs against ChoK from a specific microbe should be evaluated experimentally. Even if currently available ChoKIs do not show the desired potency against bacterial ChoKs, they can become the lead compounds for the synthesis of more effective antimicrobials. Ideally, a new generation of ChoKIs with high specificity and potency for bacterial ChoKs is generated to avoid any negative side effects on humans. More specific inhibitors are also important because human ChoKIs might not directly compete for the active sites with substrates as indicated by the mechanism of inhibition of PfChoK by HC-3, MN58 (not competitive), and RSM-932A (uncompetitive) [44]. It was even reported that TCD-717 (also known as RSM932A) did not bind directly in the choline-binding pocket of hChoK [155]. Biochemical and structural characterizations of purified bacteria ChoKs with selected inhibitors showing antimicrobial effect are still necessary to elucidate their modes of action. The same problem of AMR could also happen to ChoKIs; this is most likely through the activation of the alternative/compensatory pathway(s). Therefore, the other pathways (which could be predicted by gene sequence analysis) that might be activated to bypass the pathway involving ChoK must not be ignored.

\section{Conclusions}

We support the idea of using eukaryotic ChoKIs to inhibit prokaryotic ChoKs to battle AMR in bacteria. ChoKIs have shown promising results on S. pneumoniae by disrupting cell wall integrity that subsequently inhibited cell growth. Many disease-causing bacteria that have developed AMR possess the putative ChoK gene with highly conserved amino acid sequences at the catalytic sites. This makes them become plausible targets for currently available ChoKIs to add to the arsenal against the threat of infection by antibioticresistant bacteria. While the focus should be on the pathogenic microorganisms especially the ones that have developed AMR, there could be plenty of other applications for ChoKIs such as a relatively safe pesticide for bacteria that damage crops, i.e., agricultural applications. Biochemical characterization of more putative bacterial ChoKs would be required to confirm their activities, and basic parameters for ChoKIs such as $\mathrm{IC}_{50}$ and $\mathrm{LD}_{50}$ have to be determined to find the optimum dose of treatment. Synthesis of suitable NPs to ferry ChoKIs to the pathogen and shielding the unwanted side effects of ChoKIs from the host is also paramount to the success of the whole idea. In conclusion, more research in bacterial ChoKs would unlock the vast potential of ChoKIs as a new generation of antimicrobials, hence "choking" the pathogenic bacteria.

\section{Conflicts of Interest}

The authors declare no conflict of interest.

\section{Authors' Contributions}

M.K., L.L.F., and W.C.S.T. did the conceptualization of the study. M.K. did the writing of the original draft preparation. L.L.F. and W.C.S.T. did the writing of the review and editing. L.L.F. and W.C.S.T. did the supervision. W.C.S.T. did the project administration. L.L.F. and W.C.S.T. did the funding acquisition. All authors have read and agreed to the published version of the manuscript.

\section{Acknowledgments}

We would like to acknowledge the assistance provided by the staff of Tissue Culture Lab, Biomedical Lab, and Molecular Biology Lab at School of Health Sciences and Institute for Research in Molecular Medicine (INFORMM), Universiti Sains Malaysia. This research was funded by the Bridging Grant Scheme (304/PPSK/6316334) and the Research University Individual (RUI) Grant Scheme (1001/PPSK/8012239) from Universiti Sains Malaysia.

\section{References}

[1] A. Gupta, S. Mumtaz, C.-H. Li, I. Hussain, and V. M. Rotello, "Combatting antibiotic-resistant bacteria using nanomaterials," Chemical Society Reviews, vol. 48, no. 2, pp. 415-427, 2019.

[2] J. Davies, "Where Have all the Antibiotics Gone?," Canadian Journal of Infectious Diseases and Medical Microbiology, vol. 17, no. 5, Article ID 707296, 290 pages, 2006.

[3] D. J. Payne, M. N. Gwynn, D. J. Holmes, and D. L. Pompliano, "Drugs for bad bugs: confronting the challenges of 
antibacterial discovery," Nature Reviews. Drug Discovery, vol. 6, no. 1, pp. 29-40, 2007.

[4] C. Nathan and O. Cars, "Antibiotic Resistance-Problems, Progress, and Prospects," The New England Journal of Medicine, vol. 371, no. 19, pp. 1761-1763, 2014.

[5] J. Wojkowska-Mach, B. Godman, A. Glassman et al., "Antibiotic consumption and antimicrobial resistance in Poland; findings and implications," Antimicrobial Resistance \& Infection Control, vol. 7, no. 1, 2018.

[6] C. Llor and L. Bjerrum, "Antimicrobial resistance: risk associated with antibiotic overuse and initiatives to reduce the problem," Therapeutic Advances in Drug Safety, vol. 5, no. 6, pp. 229-241, 2014.

[7] J. Davies and D. Davies, "Origins and evolution of antibiotic resistance," Microbiology and Molecular Biology Reviews, vol. 74, no. 3, pp. 417-433, 2010.

[8] T. J. Foster, "Antibiotic resistance in Staphylococcus aureus. Current status and future prospects," FEMS Microbiology Reviews, vol. 41, no. 3, pp. 430-449, 2017.

[9] J. Brodie, M. R. Kerr, and T. Sommerville, "The Hospital Staphylococcus A Comparison of Nasal and Fæcal Carrier States," The Lancet, vol. 267, no. 6906, pp. 19-20, 1956.

[10] F. R. DeLeo, A. D. Kennedy, L. Chen et al., "Molecular differentiation of historic phage-type 80/81 and contemporary epidemic Staphylococcus aureus," Proceedings of the National Academy of Sciences, vol. 108, no. 44, pp. 18091-18096, 2011.

[11] H. F. Chambers and F. R. Deleo, "Waves of resistance: Staphylococcus aureus in the antibiotic era," Nature Reviews Microbiology, vol. 7, no. 9, pp. 629-641, 2009.

[12] M. P. Jevons, ““Celbenin”-resistant staphylococci,” British Medical Journal, vol. 1, no. 5219, pp. 124-125, 1961.

[13] E. M. Barros, M. J. Martin, E. M. Selleck, F. Lebreton, J. L. M. Sampaio, and M. S. Gilmore, "Daptomycin Resistance and Tolerance Due to Loss of Function inStaphylococcus aureusdsp1andasp23," Antimicrobial Agents and Chemotherapy, vol. 63 , no. $1,2019$.

[14] A. Endimiani, M. Blackford, E. C. Dasenbrook et al., "Emergence of linezolid-resistant Staphylococcus aureus after prolonged treatment of cystic fibrosis patients in Cleveland, Ohio," Antimicrobial Agents and Chemotherapy, vol. 55, no. 4, pp. 1684-1692, 2011.

[15] F. M. Marty, W. W. Yeh, C. B. Wennersten et al., "Emergence of a clinical daptomycin-resistant Staphylococcus aureus isolate during treatment of methicillin-resistant Staphylococcus aureus bacteremia and osteomyelitis," Journal of Clinical Microbiology, vol. 44, no. 2, pp. 595-597, 2006.

[16] T. T. Tran, J. M. Munita, and C. A. Arias, "Mechanisms of drug resistance: daptomycin resistance," Annals of the New York Academy of Sciences, vol. 1354, no. 1, pp. 32-53, 2015.

[17] L. Safa, N. Afif, H. Zied, D. Mehdi, and Y. M. Ali, "Proper use of antibiotics: situation of linezolid at the intensive care unit of the Tunisian Military Hospital," The Pan African Medical Journal, vol. 25, 2016.

[18] S. Tristram, M. R. Jacobs, and P. C. Appelbaum, "Antimicrobial resistance in Haemophilus influenzae," Clinical Microbiology Reviews, vol. 20, no. 2, pp. 368-389, 2007.

[19] T. S. Kostyanev and L. P. Sechanova, "Virulence factors and mechanisms of antibiotic resistance of haemophilus influenzae," Folia Medica, vol. 54, no. 1, pp. 19-23, 2012.

[20] P. Vacca, C. Fazio, A. Neri, L. Ambrosio, A. Palmieri, and P. Stefanelli, "Neisseria meningitidis Antimicrobial Resistance in Italy, 2006 to 2016," Antimicrobial Agents and Chemother$a p y$, vol. 62, no. 9, 2018.

[21] Y. Zouheir, T. Atany, and N. Boudebouch, "Emergence and spread of resistant $\mathrm{N}$. meningitidis implicated in invasive meningococcal diseases during the past decade (20082017)," The Journal of Antibiotics, vol. 72, no. 3, pp. 185$188,2019$.

[22] R. Cherazard, M. Epstein, T. L. Doan, T. Salim, S. Bharti, and M. A. Smith, "Antimicrobial Resistant Streptococcus pneumoniae: Prevalence, Mechanisms, and Clinical Implications," American Journal of Therapeutics, vol. 24, no. 3, pp. e361e369, 2017.

[23] L. Kim, L. McGee, S. Tomczyk, and B. Beall, "Biological and Epidemiological Features of Antibiotic-Resistant Streptococcus pneumoniae in Pre- and Post-Conjugate Vaccine Eras: a United States Perspective," Clinical Microbiology Reviews, vol. 29, no. 3, pp. 525-552, 2016.

[24] P. C. Appelbaum, A. Bhamjee, J. N. Scragg, A. F. Hallett, A. J. Bowen, and R. C. Cooper, "Streptococcus pneumoniae resistant to penicillin and chloramphenicol," The Lancet, vol. 310, no. 8046, pp. 995-997, 1977.

[25] H. M. Adams, L. R. Joyce, Z. Guan, R. L. Akins, and K. L. Palmer, "Streptococcus mitis and S. oralis Lack a Requirement for CdsA, the Enzyme Required for Synthesis of Major Membrane Phospholipids in Bacteria," Antimicrob Agents Chemother, vol. 61, no. 5, 2017.

[26] N. N. Mishra, T. T. Tran, R. Seepersaud et al., "Perturbations of Phosphatidate Cytidylyltransferase (CdsA) Mediate Daptomycin Resistance in Streptococcus mitis/oralis by a Novel Mechanism," Antimicrob Agents Chemother, vol. 61, no. 4, 2017.

[27] T. Ono, S. Shiota, K. Hirota, K. Nemoto, T. Tsuchiya, and Y. Miyake, "Susceptibilities of Oral and Nasal Isolates ofStreptococcus mitis and Streptococcus oralis to Macrolides and PCR Detection of Resistance Genes," Antimicrobial Agents and Chemotherapy, vol. 44, no. 4, pp. 1078-1080, 2000.

[28] J. M. Munita and C. A. Arias, "Mechanisms of Antibiotic Resistance," Microbiology Spectrum, vol. 4, no. 2, 2016.

[29] B. Aslam, W. Wang, M. I. Arshad et al., "Antibiotic resistance: a rundown of a global crisis," Infection and Drug Resistance, vol. Volume 11, pp. 1645-1658, 2018.

[30] L. Grigoryan, J. G. Burgerhof, F. M. Haaijer-Ruskamp et al., "Is self-medication with antibiotics in Europe driven by prescribed use?" Journal of Antimicrobial Chemotherapy, vol. 59, no. 1, pp. 152-156, 2006.

[31] S. B. Zaman, M. A. Hussain, R. Nye, V. Mehta, K. T. Mamun, and N. Hossain, "A Review on Antibiotic Resistance: Alarm Bells are Ringing," Cureus, vol. 9, no. 6, 2017.

[32] J. C. Lacal, "Choline Kinase As A Precision Medicine Target For Therapy In Cancer, Autoimmune Diseases and Malaria," Precision Medicine, vol. 1, 2015.

[33] D. Peisach, P. Gee, C. Kent, and Z. Xu, "The Crystal Structure of Choline Kinase Reveals a Eukaryotic Protein Kinase Fold," Structure, vol. 11, no. 6, pp. 703-713, 2003.

[34] D. E. Vance, "Physiological roles of phosphatidylethanolamine N -methyltransferase," Biochimica et Biophysica Acta (BBA) - Molecular and Cell Biology of Lipids, vol. 1831, no. 3, pp. 626-632, 2013.

[35] T. Zimmerman and S. Ibrahim, "Choline Kinase, A Novel Drug Target for the Inhibition of Streptococcus pneumoniae," Antibiotics, vol. 6, no. 4, p. 20, 2017. 
[36] B. Jiménez, L. del Peso, S. Montaner, P. Esteve, and J. C. Lacal, "Generation of phosphorylcholine as an essential event in the activation of Raf-1 and MAP-kinases in growth factors-induced mitogenic stimulation," Journal of Cellular Biochemistry, vol. 57, no. 1, pp. 141-149, 1995.

[37] J. G. Cannon, "Structure-activity aspects of hemicholinium-3 (HC-3) and its analogs and congeners," Medicinal Research Reviews, vol. 14, no. 5, pp. 505-531, 1994.

[38] J. C. Lacal and J. M. Campos, "Preclinical characterization of RSM-932A, a novel anticancer drug targeting the human choline kinase alpha, an enzyme involved in increased lipid metabolism of cancer cells," Molecular Cancer Therapeutics, vol. 14, no. 1, pp. 31-39, 2015.

[39] S. P. Arlauckas, A. V. Popov, and E. J. Delikatny, "Choline kinase alpha-putting the ChoK-hold on tumor metabolism," Progress in Lipid Research, vol. 63, pp. 28-40, 2016.

[40] A. Sola-Leyva, L. C. López-Cara, P. Ríos-Marco, A. Ríos, C. Marco, and M. P. Carrasco-Jiménez, "Choline kinase inhibitors EB-3D and EB-3P interferes with lipid homeostasis in HepG2 cells," Scientific Reports, vol. 9, no. 1, p. 5109, 2019.

[41] B. F. Clem, A. L. Clem, A. Yalcin et al., "A novel small molecule antagonist of choline kinase- $\alpha$ that simultaneously suppresses MAPK and PI3K/AKT signaling," Oncogene, vol. 30, no. 30, pp. 3370-3380, 2011.

[42] S. Trousil, M. Kaliszczak, Z. Schug et al., "The novel choline kinase inhibitor ICL-CCIC-0019 reprograms cellular metabolism and inhibits cancer cell growth," Oncotarget, vol. 7, no. 24, pp. 37103-37120, 2016.

[43] J. Lacal, "Choline kinase is a novel prognostic marker and a therapeutic target in human cancer," European Journal of Cancer Supplements, vol. 6, no. 9, p. 121, 2008.

[44] T. Zimmerman, C. Moneriz, A. Diez et al., "Antiplasmodial activity and mechanism of action of RSM-932A, a promising synergistic inhibitor of Plasmodium falciparum choline kinase," Antimicrobial Agents and Chemotherapy, vol. 57, no. 12, pp. 5878-5888, 2013.

[45] L. Serrán-Aguilera, H. Denton, B. Rubio-Ruiz et al., "Plasmodium falciparum Choline Kinase Inhibition Leads to a Major Decrease in Phosphatidylethanolamine Causing Parasite Death," Scientific Reports, vol. 6, no. 1, 2016.

[46] G. J. Crowther, A. J. Napuli, J. H. Gilligan et al., "Identification of inhibitors for putative malaria drug targets among novel antimalarial compounds," Molecular and Biochemical Parasitology, vol. 175, no. 1, pp. 21-29, 2011.

[47] V. Choubey, M. Guha, P. Maity et al., "Molecular characterization and localization of Plasmodium falciparum _ choline kinase," Biochimica et Biophysica Acta (BBA) - General Subjects, vol. 1760, no. 7, pp. 1027-1038, 2006.

[48] V. Choubey, P. Maity, M. Guha et al., "Inhibition of Plasmodium falciparum choline kinase by hexadecyltrimethylammonium bromide: a possible antimalarial mechanism," Antimicrobial Agents and Chemotherapy, vol. 51, no. 2, pp. 696-706, 2007.

[49] L. L. Major, H. Denton, and T. K. Smith, "Wellcome Trust-funded monographs and book chapters coupled enzyme activity and thermal shift screening of the Maybridge Rule of 3 Fragment Library against Trypanosoma brucei choline kinase; a genetically validated drug target," in Drug Discovery, H. A. El-Shemy, Ed., IntechOpen Limited, 7th floor, 10 Lower Thames Street, London, EC3R 6AF, UK, 2013.
[50] M. Guma, E. Sanchez-Lopez, A. Lodi et al., "Choline kinase inhibition in rheumatoid arthritis," Annals of the Rheumatic Diseases, vol. 74, no. 7, pp. 1399-1407, 2015.

[51] M. F. Bustamante, R. Garcia-Carbonell, K. D. Whisenant, and M. Guma, "Fibroblast-like synoviocyte metabolism in the pathogenesis of rheumatoid arthritis," Arthritis Research \& Therapy, vol. 19, no. 1, p. 110, 2017.

[52] M. Guma, S. Tiziani, and G. S. Firestein, "Metabolomics in rheumatic diseases: desperately seeking biomarkers," Nature Reviews Rheumatology, vol. 12, no. 5, pp. 269-281, 2016.

[53] E. Sanchez-Lopez, Z. Zhong, A. Stubelius et al., "Choline uptake and metabolism modulate macrophage il-1 $\beta$ and il-18 production," Cell Metabolism, vol. 29, no. 6, pp. 13501362.e7, 2019.

[54] C. Sohlenkamp and O. Geiger, "Bacterial membrane lipids: diversity in structures and pathways," FEMS Microbiology Reviews, vol. 40, no. 1, pp. 133-159, 2016.

[55] C. R. Raetz and C. Whitfield, "Lipopolysaccharide Endotoxins," Annual Review of Biochemistry, vol. 71, no. 1, pp. 635-700, 2002.

[56] N. T. Reichmann and A. Grundling, "Location, synthesis and function of glycolipids and polyglycerolphosphate lipoteichoic acid in Gram-positive bacteria of the phylum Firmicutes," FEMS Microbiology Letters, vol. 319, no. 2, pp. 97105, 2011.

[57] T. J. Silhavy, D. Kahne, and S. Walker, "The Bacterial Cell Envelope," Cold Spring Harbor Perspectives in Biology, vol. 2, no. 5, pp. a000414-a000414, 2010.

[58] Y. Kamio and H. Nikaido, "Outer membrane of Salmonella typhimurium: accessibility of phospholipid head groups to phospholipase $\mathrm{c}$ and cyanogen bromide activated dextran in the external medium," Biochemistry, vol. 15, no. 12, pp. 2561-2570, 1976.

[59] C. R. Raetz, C. M. Reynolds, M. S. Trent, and R. E. Bishop, "Lipid A Modification Systems In Gram-Negative Bacteria," Annual Review of Biochemistry, vol. 76, no. 1, pp. 295-329, 2007.

[60] E. T. Rietschel, H. W. Wollenweber, U. Zahringer, and O. Luderitz, "Lipid A, the lipid component of bacterial lipopolysaccharides: relation of chemical structure to biological activity," Klinische Wochenschrift, vol. 60, no. 14, pp. 705709, 1982.

[61] A. W. Barb and P. Zhou, "Mechanism and inhibition of LpxC: an essential zinc-dependent deacetylase of bacterial lipid A synthesis," Current Pharmaceutical Biotechnology, vol. 9, no. 1, pp. 9-15, 2008.

[62] P. Zhou and J. Zhao, "Structure, inhibition, and regulation of essential lipid A enzymes," Biochimica et Biophysica Acta (BBA) - Molecular and Cell Biology of Lipids, vol. 1862, no. 11, pp. 1424-1438, 2017.

[63] L. Wang, Y.-L. Jiang, J.-R. Zhang, C.-Z. Zhou, and Y. Chen, "Structural and enzymatic characterization of the choline kinase LicA from Streptococcus pneumoniae," PLoS One, vol. 10, no. 3, 2015.

[64] A. Tomasz, "Choline in the cell wall of a bacterium: novel type of polymer-linked choline in Pneumococcus," Science, vol. 157, no. 3789, pp. 694-697, 1967.

[65] G. C. Whiting and S. H. Gillespie, "Incorporation of choline into Streptococcus pneumoniae cell wall antigens: evidence for choline kinase activity," FEMS Microbiology Letters, vol. 138, no. 2-3, pp. 141-145, 1996. 
[66] S. F. Elswaifi, F. S. Michael, A. Sreenivas, A. Cox, G. M. Carman, and T. J. Inzana, "Molecular characterization of phosphorylcholine expression on the lipooligosaccharide of Histophilus somni," Microbial Pathogenesis, vol. 47, no. 4, pp. 223-230, 2009.

[67] D. Denapaite, R. Bruckner, R. Hakenbeck, and W. Vollmer, "Biosynthesis of teichoic acids in Streptococcus pneumoniae and closely related species: lessons from genomes," Microbial Drug Resistance, vol. 18, no. 3, pp. 344-358, 2012.

[68] N. Gisch, T. Kohler, A. J. Ulmer et al., "Structural reevaluation of Streptococcus pneumoniae Lipoteichoic acid and new insights into its immunostimulatory potency," Journal of Biological Chemistry, vol. 288, no. 22, pp. 15654-15667, 2013.

[69] N. Gisch, D. Schwudke, S. Thomsen, N. Hess, R. Hakenbeck, and D. Denapaite, "Lipoteichoic acid of Streptococcus oralis Uo5: a novel biochemical structure comprising an unusual phosphorylcholine substitution pattern compared to Streptococcus pneumoniae," Scientific Reports, vol. 5, no. 1, 2015.

[70] N. Bergstrom, P. E. Jansson, M. Kilian, and U. B. Skov Sorensen, "Structures of two cell wall-associated polysaccharides of a Streptococcus mitis biovar 1 strain. A unique teichoic acid-like polysaccharide and the group $\mathrm{O}$ antigen which is a C-polysaccharide in common with pneumococci," European Journal of Biochemistry, vol. 267, no. 24, pp. 7147-7157, 2000.

[71] I. Ginsburg, "Role of lipoteichoic acid in infection and inflammation," The Lancet Infectious Diseases, vol. 2, no. 3, pp. 171-179, 2002.

[72] G. Zhang, T. C. Meredith, and D. Kahne, "On the essentiality of lipopolysaccharide to Gram-negative bacteria," Current Opinion in Microbiology, vol. 16, no. 6, pp. 779-785, 2013.

[73] S. Galán-Bartual, I. Pérez-Dorado, P. García, and J. A. Hermoso, "Structure and Function of Choline-Binding Proteins," in Streptococcus Pneumoniae, J. Brown, S. Hammerschmidt, and C. Orihuela, Eds., pp. 207-230, Academic Press, Amsterdam, 2015.

[74] N. M. Young, S. J. Foote, and W. W. Wakarchuk, "Review of phosphocholine substituents on bacterial pathogen glycans: synthesis, structures and interactions with host proteins," Molecular Immunology, vol. 56, no. 4, pp. 563-573, 2013.

[75] E. S. Lysenko, J. Gould, R. Bals, J. M. Wilson, and J. N. Weiser, "Bacterial phosphorylcholine decreases susceptibility to the antimicrobial peptide LL-37/hCAP18 expressed in the upper respiratory tract," Infection and Immunity, vol. 68, no. 3, pp. 1664-1671, 2000.

[76] S. E. Clark, J. Snow, J. Li, T. A. Zola, and J. N. Weiser, "Phosphorylcholine allows for evasion of bactericidal antibody by Haemophilus influenzae," PLOS Pathogens, vol. 8, no. 3, 2012.

[77] W. Harnett, J. Rzepecka, and K. M. Houston, "How do nematodes transfer phosphorylcholine to carbohydrates?," Trends in Parasitology, vol. 26, no. 3, pp. 114-118, 2010.

[78] S. E. Clark and J. N. Weiser, "Microbial modulation of host immunity with the small molecule phosphorylcholine," Infection and Immunity, vol. 81, no. 2, pp. 392-401, 2013.

[79] W. E. Swords, B. A. Buscher, K. V. S. Ii et al., "Non-typeable Haemophilus influenzae adhere to and invade human bronchial epithelial cells via an interaction of lipooligosaccharide with the PAF receptor," Molecular Microbiology, vol. 37, no. 1, pp. 13-27, 2000.
[80] A. S. Kharat and A. Tomasz, "Drastic reduction in the virulence of Streptococcus pneumoniae expressing type 2 capsular polysaccharide but lacking choline residues in the cell wall," Molecular Microbiology, vol. 60, no. 1, pp. 93-107, 2006.

[81] R. Lopez and E. Garcia, "Recent trends on the molecular biology of pneumococcal capsules, lytic enzymes, and bacteriophage," FEMS Microbiology Reviews, vol. 28, no. 5, pp. 553-580, 2004.

[82] W. Fischer, "Phosphocholine of pneumococcal teichoic acids: role in bacterial physiology and pneumococcal infection," Research in Microbiology, vol. 151, no. 6, pp. 421-427, 2000.

[83] C. Sohlenkamp, I. M. Lopez-Lara, and O. Geiger, "Biosynthesis of phosphatidylcholine in bacteria," Progress in Lipid Research, vol. 42, no. 2, pp. 115-162, 2003.

[84] O. Geiger, I. M. Lopez-Lara, and C. Sohlenkamp, "Phosphatidylcholine biosynthesis and function in bacteria," Biochimica et Biophysica Acta (BBA)-Molecular and Cell Biology of Lipids, vol. 1831, no. 3, pp. 503-513, 2013.

[85] M. Bogdanov, M. Umeda, and W. Dowhan, "Phospholipidassisted refolding of an integral membrane protein. Minimum structural features for phosphatidylethanolamine to act as a molecular chaperone," The Journal of Biological Chemistry, vol. 274, no. 18, pp. 12339-12345, 1999.

[86] L. R. Joyce, Z. Guan, and K. L. Palmer, "Phosphatidylcholine Biosynthesis in Mitis Group Streptococci via Host Metabolite Scavenging," Journal of Bacteriology, vol. 201, no. 22, 2019.

[87] G. M. Conover, F. Martinez-Morales, M. I. Heidtman et al., "Phosphatidylcholine synthesis is required for optimal function of Legionella pneumophila virulence determinants," Cellular Microbiology, vol. 10, no. 2, pp. 514-528, 2007.

[88] D. J. Comerci, S. Altabe, D. de Mendoza, and R. A. Ugalde, "Brucella abortus synthesizes phosphatidylcholine from choline provided by the host," Journal of Bacteriology, vol. 188, no. 5, pp. 1929-1934, 2006.

[89] M. Aktas, L. Danne, P. Möller, and F. Narberhaus, "Membrane lipids in Agrobacterium tumefaciens: biosynthetic pathways and importance for pathogenesis," Frontiers in Plant Science, vol. 5, p. 109, 2014.

[90] A. A. Malek, M. J. Wargo, and D. A. Hogan, "Absence of membrane phosphatidylcholine does not affect virulence and stress tolerance phenotypes in the opportunistic pathogen Pseudomonas aeruginosa," PLoS One, vol. 7, no. 2, p. e30829, 2012.

[91] B. Maestro and J. Sanz, "Choline binding proteins from Streptococcus pneumoniae: a dual role as enzybiotics and targets for the design of new antimicrobials," Antibiotics, vol. 5, no. 2, p. 21, 2016.

[92] T. Zimmerman, J. C. Lacal, and S. A. Ibrahim, "Choline kinase emerges as a promising drug target in Gram-positive bacteria," Frontiers in Microbiology, vol. 6, 2019.

[93] X. Fan, C. D. Pericone, E. Lysenko, H. Goldfine, and J. N. Weiser, "Multiple mechanisms for choline transport and utilization in Haemophilus influenzae," Molecular Microbiology, vol. 50, no. 2, pp. 537-548, 2003.

[94] J. R. Zhang, I. Idanpaan-Heikkila, W. Fischer, and E. I. Tuomanen, "Pneumococcal licD2 gene is involved in phosphorylcholine metabolism," Molecular Microbiology, vol. 31, no. 5, pp. 1477-1488, 1999.

[95] F. Waldow, T. P. Kohler, N. Heß, D. Schwudke, S. Hammerschmidt, and N. Gisch, "Attachment of 
phosphorylcholine residues to pneumococcal teichoic acids and modification of substitution patterns by the phosphorylcholine esterase," Journal of Biological Chemistry, vol. 293, no. 27, pp. 10620-10629, 2018.

[96] M. Damjanovic, A. S. Kharat, A. Eberhardt, A. Tomasz, and W. Vollmer, "The essential tacF gene is responsible for the choline-dependent growth phenotype of Streptococcus pneumoniae," Journal of Bacteriology, vol. 189, no. 19, pp. 71057111, 2007.

[97] M. Á. Vences-Guzmán, M. Paula Goetting-Minesky, Z. Guan et al., "1,2-Diacylglycerol choline phosphotransferase catalyzes the final step in the unique Treponema denticola phosphatidylcholine biosynthesis pathway," Molecular Microbiology, vol. 103, no. 5, pp. 896-912, 2017.

[98] R. Moser, M. Aktas, and F. Narberhaus, "Phosphatidylcholine biosynthesis in $X$ anthomonas campestris via a yeastlike acylation pathway," Molecular Microbiology, vol. 91, no. 4, pp. 736-750, 2014.

[99] K. E. E. de Rudder, C. Sohlenkamp, and O. Geiger, "Plantexuded choline is used for rhizobial membrane lipid biosynthesis by phosphatidylcholine synthase," The Journal of Biological Chemistry, vol. 274, no. 28, pp. 20011-20016, 1999.

[100] H. Homma and S. Nojima, "Transacylation between diacylphospholipids and 2-acyl lysophospholipids catalyzed by Escherichia coli extract," The Journal of Biochemistry, vol. 91, no. 4, pp. 1093-1101, 1982.

[101] M. L. Ancelin, M. Calas, J. Bompart et al., “Antimalarial activity of 77 phospholipid polar head analogs: close correlation between inhibition of phospholipid metabolism and in vitro Plasmodium falciparum growth," Blood, vol. 91, no. 4, pp. 1426-1437, 1998.

[102] M. Montazeri, S. Mehrzadi, M. Sharif et al., "Drug resistance in Toxoplasma gondii," Frontiers in Microbiology, vol. 9, p. 2587, 2018.

[103] V. Sampels, A. Hartmann, I. Dietrich et al., "Conditional mutagenesis of a novel choline kinase demonstrates plasticity of phosphatidylcholine biogenesis and gene expression in Toxoplasma gondii," The Journal of Biological Chemistry, vol. 287, no. 20, pp. 16289-16299, 2012.

[104] B. A. Fox and D. J. Bzik, "De novo pyrimidine biosynthesis is required for virulence of Toxoplasma gondii," Nature, vol. 415, no. 6874, pp. 926-929, 2002.

[105] M. Blume, D. Rodriguez-Contreras, S. Landfear et al., "Host-derived glucose and its transporter in the obligate intracellular pathogen Toxoplasma gondii are dispensable by glutaminolysis," Proceedings of the National Academy of Sciences of the United States of America, vol. 106, no. 31, pp. 12998-13003, 2009.

[106] C. C. Han, Biomedical characterization of Entamoeba histolytica choline/ethanolamine kinases, P. P. S. Kesihatan, Ed., Universiti Sains Malaysia, Kota Bharu, Malaysia, 2012.

[107] J. M. Jez, "Phosphatidylcholine biosynthesis as a potential target for inhibition of metabolism in parasitic nematodes," Current Enzyme Inhibition, vol. 3, no. 2, pp. 133142, 2007.

[108] S. Moitra, M. C. Pawlowic, F.-f. Hsu, and K. Zhang, "Phosphatidylcholine synthesis through cholinephosphate cytidylyltransferase is dispensable in Leishmania major," Scientific Reports, vol. 9, no. 1, p. 7602, 2019.

[109] E. Malito, N. Sekulic, W. C. Too, M. Konrad, and A. Lavie, "Elucidation of human choline kinase crystal structures in complex with the products ADP or phosphocholine," Journal of Molecular Biology, vol. 364, no. 2, pp. 136-151, 2006.

[110] B. S. Hong, A. Allali-Hassani, W. Tempel et al., "Crystal structures of human choline kinase isoforms in complex with hemicholinium-3: single amino acid near the active site influences inhibitor sensitivity," The Journal of Biological Chemistry, vol. 285, no. 21, pp. 16330-16340, 2010.

[111] F. Sievers, A. Wilm, D. Dineen et al., "Fast, scalable generation of high-quality protein multiple sequence alignments using Clustal Omega," Molecular Systems Biology, vol. 7, no. 1, pp. 539-539, 2011.

[112] J. N. Weiser, M. Shchepetov, and S. T. Chong, "Decoration of lipopolysaccharide with phosphorylcholine: a phase-variable characteristic of Haemophilus influenzae," Infection and Immunity, vol. 65, no. 3, pp. 943-950, 1997.

[113] J. N. Weiser, J. M. Love, and E. R. Moxon, "The molecular mechanism of phase variation of $\mathrm{H}$. influenzae lipopolysaccharide," Cell, vol. 59, no. 4, pp. 657-665, 1989.

[114] C. K. Herrmann, L. Bukata, L. Melli, M. I. Marchesini, J. J. Caramelo, and D. J. Comerci, "Identification and characterization of a high-affinity choline uptake system of Brucella abortus," Journal of Bacteriology, vol. 195, no. 3, pp. 493501, 2013.

[115] M. J. Wargo, "Homeostasis and catabolism of choline and glycine betaine: lessons from Pseudomonas aeruginosa," Applied and Environmental Microbiology, vol. 79, no. 7, pp. 2112-2120, 2013.

[116] S. Craciun and E. P. Balskus, "Microbial conversion of choline to trimethylamine requires a glycyl radical enzyme," Proceedings of the National Academy of Sciences of the United States of America, vol. 109, no. 52, pp. 21307-21312, 2012.

[117] E. A. Ennis, J. Wright, C. L. Retzlaff et al., "Identification and characterization of ML352: a novel, noncompetitive inhibitor of the presynaptic choline transporter," ACS Chemical Neuroscience, vol. 6, no. 3, pp. 417-427, 2015.

[118] R. M. Kappes, B. Kempf, S. Kneip et al., "Two evolutionarily closely related $\mathrm{ABC}$ transporters mediate the uptake of choline for synthesis of the osmoprotectant glycine betaine in Bacillus subtilis," Molecular Microbiology, vol. 32, no. 1, pp. 203-216, 1999.

[119] R. M. Kappes, B. Kempf, and E. Bremer, "Three transport systems for the osmoprotectant glycine betaine operate in Bacillus subtilis: characterization of OpuD," Journal of Bacteriology, vol. 178, no. 17, pp. 5071-5079, 1996.

[120] E. P. O'Grady and P. A. Sokol, "Burkholderia cenocepacia differential gene expression during host-pathogen interactions and adaptation to the host environment," Frontiers in Cellular and Infection Microbiology, vol. 1, pp. 15-15, 2011.

[121] H. E. Daligault, K. W. Davenport, T. D. Minogue et al., "Whole-genome assemblies of 56 burkholderia species," Genome Announcements, vol. 2, no. 6, pp. e01106-e01114, 2014.

[122] E. Dahlsten, M. Isokallio, P. Somervuo, M. Lindström, and H. Korkeala, "Transcriptomic analysis of (group I) Clostridium botulinum ATCC 3502 cold shock response," PLoS One, vol. 9, no. 2, pp. e89958-e89958, 2014.

[123] M. Sebaihia, M. W. Peck, N. P. Minton et al., "Genome sequence of a proteolytic (Group I) Clostridium botulinum strain Hall A and comparative analysis of the clostridial genomes," Genome research, vol. 17, no. 7, pp. 1082-1092, 2007. 
[124] G. Pranavathiyani, J. Prava, A. C. Rajeev, and A. Pan, "Novel target exploration from hypothetical proteins of Klebsiella pneumoniae MGH 78578 reveals a protein involved in host-pathogen interaction," Frontiers in Cellular and Infection Microbiology, vol. 10, pp. 109-109, 2020.

[125] V. Weterings, K. Zhou, J. W. Rossen et al., "An outbreak of colistin-resistant Klebsiella pneumoniae carbapenemaseproducing Klebsiella pneumoniae in the Netherlands (July to December 2013), with inter-institutional spread," European Journal of Clinical Microbiology \& Infectious Diseases, vol. 34, no. 8, pp. 1647-1655, 2015.

[126] N. S. Shah, S. C. Auld, J. C. M. Brust et al., "Transmission of extensively drug-resistant tuberculosis in South Africa," The New England Journal of Medicine, vol. 376, no. 3, pp. 243253, 2017.

[127] J. Youm and M. H. Saier Jr., "Comparative analyses of transport proteins encoded within the genomes of Mycobacterium tuberculosis and Mycobacterium leprae," Biochimica et Biophysica Acta, vol. 1818, no. 3, pp. 776-797, 2012.

[128] L. Serino and M. Virji, "Phosphorylcholine decoration of lipopolysaccharide differentiates commensal Neisseriae from pathogenic strains: identification of licA-type genes in commensal Neisseriae," Molecular Microbiology, vol. 35, no. 6, pp. 1550-1559, 2000.

[129] J. N. Weiser, J. B. Goldberg, N. Pan, L. Wilson, and M. Virji, "The phosphorylcholine epitope undergoes phase variation on a 43-kilodalton protein in Pseudomonas aeruginosa and on pili of Neisseria meningitidis and Neisseria gonorrhoeae," Infection and Immunity, vol. 66, no. 9, pp. 4263-4267, 1998.

[130] M. J. Warren and M. P. Jennings, "Identification and characterization of pptA: a gene involved in the phase-variable expression of phosphorylcholine on pili of Neisseria meningitidis," Infection and Immunity, vol. 71, no. 12, pp. 68926898, 2003

[131] A. A. Malek, C. Chen, M. J. Wargo, G. A. Beattie, and D. A. Hogan, "Roles of three transporters, CbcXWV, BetT1, and BetT3, in Pseudomonas aeruginosa choline uptake for catabolism," Journal of Bacteriology, vol. 193, no. 12, pp. 30333041, 2011.

[132] A. Kaenjak, J. E. Graham, and B. J. Wilkinson, "Choline transport activity in Staphylococcus aureus induced by osmotic stress and low phosphate concentrations," Journal of Bacteriology, vol. 175, no. 8, pp. 2400-2406, 1993.

[133] C. Kent, P. Gee, S. Y. Lee, X. Bian, and J. C. Fenno, “A CDPcholine pathway for phosphatidylcholine biosynthesis in Treponema denticola," Molecular Microbiology, vol. 51, no. 2, pp. 471-481, 2004.

[134] D. Kapfhammer, E. Karatan, K. J. Pflughoeft, and P. I. Watnick, "Role for glycine betaine transport in Vibrio cholerae osmoadaptation and biofilm formation within microbial communities," Applied and Environmental Microbiology, vol. 71, no. 7, pp. 3840-3847, 2005.

[135] S. Y. Ongagna-Yhombi, N. D. McDonald, and E. F. Boyd, "Deciphering the role of multiple betaine-carnitine-choline transporters in the Halophile Vibrio parahaemolyticus," Applied and Environmental Microbiology, vol. 81, no. 1, pp. 351-363, 2015.

[136] R. Singh and J. W. Lillard Jr., "Nanoparticle-based targeted drug delivery," Experimental and Molecular Pathology, vol. 86, no. 3, pp. 215-223, 2009.

[137] P. V. Baptista, M. P. McCusker, A. Carvalho et al., "Nanostrategies to fight multidrug resistant bacteria-"A Battle of the Titans"," Frontiers in Microbiology, vol. 9, no. 1441, pp. 1441-1441, 2018.

[138] D. Bobo, K. J. Robinson, J. Islam, K. J. Thurecht, and S. R. Corrie, "Nanoparticle-based medicines: a review of FDAapproved materials and clinical trials to date," Pharmaceutical Research, vol. 33, no. 10, pp. 2373-2387, 2016.

[139] N.-Y. Lee, W.-C. Ko, and P.-R. Hsueh, "Nanoparticles in the treatment of infections caused by multidrug-resistant organisms," Frontiers in Pharmacology, vol. 10, 2019.

[140] Y.-C. Yeh, T. H. Huang, S. C. Yang, C. C. Chen, and J. Y. Fang, "Nano-based drug delivery or targeting to eradicate bacteria for infection mitigation: a review of recent advances," Frontiers in Chemistry, vol. 8, pp. 286-286, 2020.

[141] W. Gao, Y. Chen, Y. Zhang, Q. Zhang, and L. Zhang, "Nanoparticle-based local antimicrobial drug delivery," Advanced Drug Delivery Reviews, vol. 127, pp. 46-57, 2018.

[142] A. F. Radovic-Moreno, T. K. Lu, V. A. Puscasu, C. J. Yoon, R. Langer, and O. C. Farokhzad, "Surface charge-switching polymeric nanoparticles for bacterial cell wall-targeted delivery of antibiotics," ACS Nano, vol. 6, no. 5, pp. 4279-4287, 2012.

[143] J. R. Morones-Ramirez, J. A. Winkler, C. S. Spina, and J. J. Collins, "Silver enhances antibiotic activity against gramnegative bacteria," Science Translational Medicine, vol. 5, no. 190, p. 190ra81, 2013.

[144] L. Wang, C. Hu, and L. Shao, "The antimicrobial activity of nanoparticles: present situation and prospects for the future," International Journal of Nanomedicine, vol. Volume 12, pp. 1227-1249, 2017.

[145] S. Neethirajan, M. A. Clond, and A. Vogt, "Medical biofilmsnanotechnology approaches," Journal of Biomedical Nanotechnology, vol. 10, no. 10, pp. 2806-2827, 2014.

[146] S. C. Esparza-Gonzalez, S. Sanchez-Valdes, S. N. RamirezBarron et al., "Effects of different surface modifying agents on the cytotoxic and antimicrobial properties of $\mathrm{ZnO}$ nanoparticles," Toxicology In Vitro, vol. 37, pp. 134-141, 2016.

[147] S. Katva, S. Das, H. S. Moti, A. Jyoti, and S. Kaushik, "Antibacterial synergy of silver nanoparticles with gentamicin and chloramphenicol against Enterococcus faecalis," Pharmacognosy Magazine, vol. 13, Supplement 4, pp. S828-s833, 2018.

[148] D. Lombardo, M. A. Kiselev, and M. T. Caccamo, "Smart nanoparticles for drug delivery application: development of versatile nanocarrier platforms in biotechnology and nanomedicine," Journal of Nanomaterials, vol. 2019, 26 pages, 2019.

[149] L. E. van Vlerken and M. M. Amiji, "Multi-functional polymeric nanoparticles for tumour-targeted drug delivery," Expert Opinion on Drug Delivery, vol. 3, no. 2, pp. 205-216, 2006.

[150] A. Bassegoda, K. Ivanova, E. Ramon, and T. Tzanov, "Strategies to prevent the occurrence of resistance against antibiotics by using advanced materials," Applied Microbiology and Biotechnology, vol. 102, no. 5, pp. 2075-2089, 2018.

[151] S. Hussain, J. Joo, J. Kang et al., “Antibiotic-loaded nanoparticles targeted to the site of infection enhance antibacterial efficacy," Nature Biomedical Engineering, vol. 2, no. 2, pp. 95-103, 2018.

[152] D. S. W. Benoit, K. R. Sims Jr., and D. Fraser, "Nanoparticles for oral biofilm treatments," ACS Nano, vol. 13, no. 5, pp. 4869-4875, 2019. 
[153] M. A. Dos Santos Ramos, P. da Silva, L. Spósito et al., "Nanotechnology-based drug delivery systems for control of microbial biofilms: a review," International Journal of Nanomedicine, vol. Volume 13, pp. 1179-1213, 2018.

[154] A. L. Armstead and B. Li, "Nanomedicine as an emerging approach against intracellular pathogens," International Journal of Nanomedicine, vol. 6, pp. 3281-3293, 2011.

[155] S. L. Kall, E. J. Delikatny, and A. Lavie, "Identification of a unique inhibitor-binding site on choline kinase $\alpha$," Biochemistry, vol. 57, no. 8, pp. 1316-1325, 2018. 